\title{
Research Insights on Climate and Water in the Hindu Kush Himalayas
}

Editors

Ramesh Ananda Vaidya

Eklabya Sharma 


\section{Copyright $(\subset) 2014$}

International Centre for Integrated Mountain Development (ICIMOD)

All rights reserved, Published 2014

\section{Published by}

International Centre for Integrated Mountain Development, GPO Box 3226, Kathmandu, Nepal

ISBN 9789291152964 (printed) 9789291152971 (electronic)

Library of Congress Control Number 2013-310103

\section{Production team}
A Beatrice Murray (Consultant editor)
Amy Sellmyer (Editor)
Dharma R Maharjan (Graphic designer)
Asha Kaji Thaku (Editorial assistance)

\section{Photos}

Photos: Nabin Baral

\section{Printed and bound in Nepal by}

Hill Side Press (P) Ltd., Kathmandu, Nepal

\section{Reproduction}

This publication may be reproduced in whole or in part and in any form for educational or non-profit purposes without special permission from the copyright holder, provided acknowledgement of the source is made. ICIMOD would appreciate receiving a copy of any publication that uses this publication as a source. No use of this publication may be made for resale or for any other commercial purpose whatsoever without prior permission in writing from ICIMOD.

\section{Note}

The views and interpretations in this publication are those of the author(s). They are not attributable to ICIMOD and do not imply the expression of any opinion concerning the legal status of any country, territory, city or area of its authorities, or concerning the delimitation of its frontiers or boundaries, or the endorsement of any product.

This publication is available in electronic form at www.icimod.org/himaldoc

Citation: Vaidya, RA; Sharma, E (eds) (2014) Research insights on climate and water in the Hindu Kush Himalayas. Kathmandu: ICIMOD 


\section{Contents}

Foreword

Preface vi vi vili

Acknowledgements viii

Acronyms and Abbreviations $\quad x$

Part I - Synthesis

Research Insights on Climate Change and Water Resources Management in the Hindu Kush Himalayas

Ramesh A Vaidya, Eklabya Sharma, Bhaskar S Karky, Rajan Kotru, Pradeep Mool, Aditi Mukherii,

Neera S Pradhan, Arun B Shrestha, Shariar Wahid, and David Molden

\section{Part II - Research Papers}

Estimation of Discharge from Glacierized River Basins: Case Studies from Langtang Valley, Nepal and Kafni River Basin, India

Rijan Bhakta Kayastha, Rajesh Kumar, Damodar Lamsal, Shaktiman Singh, Kundan Lal Shrestha,

Arun Bhakta Shrestha, and Sunil Kumar Pariyar

Vulnerability Assessment of Flash Floods in Poiqu/Bhotekoshi/Sunkoshi Watershed

Narendra Raj Khanal, Jin-Ming Hu, Jie Cao, Hridaya L Koirala, Yun-Gang Li, Pashupati Nepal, Jie Li,

Hai-Feng Jia, and Pradeep KMool

The Impacts of Climate Change on Water Stress Situations in the

Yellow River Basin, China

Jianxin Mu, Liu Qunchang, Hamza Farooq Gabriel, Xu Di, Xu Jingdong, Wu Caili, and Ren Hejing

Climate Change and Water Availability in the Ganges-Brahmaputra-

Meghna Basin: Impact on Local Crop Production and Policy Directives

Ahmadul Hassan, Shahriar Wahid, Madan Lal Shrestha, Mohammad Abdur Rashid, Tanvir Ahmed,

Anushila Mazumder, Motaleb Hossain Sarker, Bhuiya Md. Tamim Al Hossain, Sarazina Mumu, and

Maminul Haque Sarker

Climate Change Impact on Water Availability, and Farmers'

Adaptation Strategies: Case Studies from Pakistan and Nepal

Suman Sijapati, Muhammad Tousif Bhatti, and Neera Shrestha Pradhan

People's Perceptions of and Adaptation Strategies to Climate Change

in the Koshi River Basin, Nepal

Xiaoliu Yang, Narendra Raj Khanal, Hriday Lal Koirala, and Pashupati Nepal

Benefit Sharing Mechanisms in Hydropower Projects: Lessons from

Nepal and India

Dhruba Pant, Neena Rao, Surya Nath Upadhyaya, and Bhaskar Singh Karky

Research Note: A Preliminary Investigation of Spatial Variability and Stable Isotope Content of Monsoon Rainfall in the Lesser Himalayas, Northern India:

A Microwatershed Perspective

S Tarafdar, GCS Negi, KL Shrestha, and Rajan Kotru 


\section{Foreword}

Managing water resources is one of the major challenges of our century. Nowhere could this be more so than for the waters emanating from the Hindu Kush Himalayas that serve over 1.3 billion people providing food, energy, household water supplies, and numerous other ecosystem services. The Hindu Kush Himalayan region is already characterized by a situation of 'too much and too little' water. Floods and droughts are already common, and the economic damage from these hazards is already high. Moreover, in some of the more arid areas, the situation of water scarcity is already being felt and is growing. In other areas, water in the rivers is seemingly abundant, but access to water for drinking, growing food, and obtaining energy is challenging for many rural people. Water access is a major concern for mountain and hill dwellers.

With a growing population, more urbanization, and increasing wealth, our demand for this resource is increasing. Yet with climate change, the situation of water supply remains uncertain with changing precipitation and snowmelt patterns. To adapt to this changing situation, well conceived investments are required, in addition to improvements in water governance and management. It is essential that more scientific results are generated and used to make more informed decisions about this crucial resource.

The water resources of the Hindu Kush Himalayas are a shared resource in many ways. They are shared between upstream and downstream users, between people and nature, and between countries. This shared nature of the resource brings the promise of multiple benefits, but also the threat of increased conflict. To realize the benefits of water resources, it is essential that there is a shared understanding of the resource. The South Asia Water Initiative Small Grants Program, whose results are reported here, was a particularly valuable exercise in that while it contributed to science and understanding, it also promoted a shared vision of water resource management by bringing researchers together from different countries in the region.

ICIMOD's mission is to enable sustainable and resilient mountain development for improved and equitable livelihoods through knowledge and regional cooperation. Over the past three decades, ICIMOD has provided a common platform for regional cooperation where policy makers, experts, planners, and practitioners exchange scientific data, information, ideas, and perspectives towards achieving common solutions at regional levels. Water issues, along with concerns of livelihoods and ecosystems, are integrated across ICIMOD's regional programmes addressing adaptation to change, transboundary landscapes, river basins, cryosphere and atmosphere, and regional information collection and sharing. ICIMOD also supports transboundary collaborative research among its regional member countries through its projects.

We would like to thank the World Bank for our involvement in the South Asia Water Initiative. Through its Small Grants Program, a new dimension has been added to ICIMOD's activities to promote new knowledge generation in the region. Through this programme we were able to mobilize partners to advance knowledge and regional cooperation to contribute to strategies that 
will ultimately improve livelihoods. The programme has helped in promoting South-South cooperation in the $\mathrm{HKH}$ region for collaborative research among its knowledge institutions - a practice that helps to propagate regional research partnerships with multiplier effects. It has also helped in capacity building in those institutions on water resources research, especially in using climate and hydrological models for policy-relevant investigations. We hope such collaborative research between the institutions in different countries of the region will ultimately lead to 'goal congruence' among the different nations on issues concerning water resources development and management.

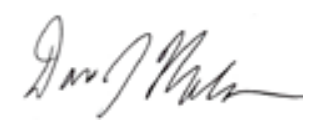

David Molden, PhD

Director General, ICIMOD 


\section{Preface}

The great rivers of South Asia - including the Indus, Ganges, and Brahmaputra that traverse Afghanistan, Bangladesh, Bhutan, China, India, Nepal, and Pakistan - are critical to maintaining livelihoods and ecosystems and have a vast potential for producing food and clean energy. Regional water cooperation on these river systems has often been hindered by the lack of a sound knowledge base on the availability of resources and their distribution over space and time, and a lack of understanding of the impacts of various drivers of change on the supply and demand of resources - for example, the impacts of climate change on stream flow variability, sedimentation, and potential GLOF events.

The South Asia Water Initiative (SAWI) is a partnership established in 2009 between the World Bank and the governments of the United Kingdom, Australia, and Norway with the specific objective "to increase regional cooperation in the management of the Himalayan River systems to deliver sustainable, fair and inclusive development and climate resilience". It was established as a multi-donor trust fund financed by the three governments and administered by the World Bank. During 2009-2013, a Small Grants Programme was included as one of the activities, and administered by the International Centre for Integrated Mountain Development (ICIMOD). The idea for such a programme was conceived in 2008 at the first Abu Dhabi Dialogue Knowledge Forum (ADDKF) organized by the Abu Dhabi Dialogue Group, a partnership of senior members of government, academia, and civil society from the seven countries that share the rivers of the greater Himalayas, with technical support from ICIMOD. Participants at the Forum came from more than 50 knowledge institutions.

Following the deliberations and subsequent discussions during the Abu Dhabi Dialogue (ADD) meetings in 2009 and 2010, the Small Grants Programme was established to support knowledge generation and dissemination on the rivers of the greater Himalayas. The objectives of the Small Grants Programme were (a) to facilitate the quest to increase knowledge about water resource systems and their uses within the realm of the greater Himalayas, which are under particular stress from climate change and other drivers of change, including those arising from population and economic growth; (b) to facilitate collaboration among knowledge institutions from different countries sharing the rivers of the greater Himalayas; and (c) to support these institutions to work together in a collaborative manner. The priority topics of interest in the context of water resource systems and their uses were (a) vulnerability, adaptation and impacts of climate change, (b) integrated ecosystems and river basin management, including benefit sharing; (c) upstream-downstream impacts of water storage projects; and (d) the management of water for enhancing food security. The eligibility criteria required that the funded proposals include two or more knowledge institutions from two or more SAWI countries - Afghanistan, Bangladesh, Bhutan, China, India, Nepal, and Pakistan - had high relevance for river basin management and benefit sharing in the region, particularly in line with the priority topics of interest, and provided a spirit of regional cooperation and knowledge sharing. 
The Small Grants Programme was officially launched in March 2011 , when representatives of 40 research institutions from across the seven SAWI countries convened. The launch programme facilitated new partnerships between knowledge institutions from different countries, many of which had no prior history of formal interaction. Subsequently, a call for proposals was made. Twenty-three of the 39 proposals received met the SGP eligibility criteria, and they were reviewed and ranked by international technical experts and a Technical Assessment Panel comprised of representatives from ICIMOD and the World Bank and the SAWI donor representative. The Technical Assessment Panel recommended eight proposals for funding; these were shared with ADD members for comments and suggestions, and subsequently approved.

In this volume, we present seven research papers and a note drawing on the final technical reports of the eight funded projects. These are preceded by a synthesis of the key findings of the research papers. We have three objectives in mind for publishing these papers. First, we felt that they will be of interest to scientists and policymakers in the SAWI countries to the extent that they reflect new knowledge on regional solutions to regional problems - generated by the knowledge institutions in the region itself. Second, it may be of interest to scientists and policymakers in the region to learn about the contribution the Small Grants Programme has made to capacity building of the knowledge institutions for scientific and policy-relevant research and to developing a regional network of those institutions for collaborative research. Third, such a participatory process of knowledge institutions from different countries working on common problems of regional concern may have important implications for promoting regional water cooperation in the Hindu Kush Himalayan region. 


\section{Acknowledgements}

The Small Grants Programme (SGP) was funded by the South Asia Water Initiative (SAWI), a programme of the World Bank with support from the governments of the United Kingdom, Australia, and Norway. We would like to acknowledge their support to this programme.

During the conception stage of the programme, we received valuable support from Dr David Grey and Dr Claudia Sadoff at the World Bank and Dr Andreas Schild and Dr Mats Eriksson at ICIMOD. During the proposal selection process, we received support from the chair and members of the SGP Technical Assessment Panel: Dr Madhav Karki (Chair) and Dr Hua Ouyang at ICIMOD, Dr Guy Howard at the Department for International Development, UK (DFID), and Ms Catherine Revels and Ms Stephanie Borsboom at the World Bank.

For the proposal selection process, we also received valuable support from international experts in reviewing the proposals: Professor AK Gosain at the Indian Institute of Technology, Delhi; Dr Walter Immerzeel at Futurewater, the Netherlands; Dr RPS Malik at the International Water Management Institute, Delhi; and Professor Peter Rogers at Harvard University, USA.

For the internal review of the proposals received and the quality assurance process of the funded proposals, we received support from our ICIMOD colleagues: Dr Bhaskar Karky; Dr Rajan Kotru; Mr Pradeep Mool; Dr Aditi Mukherii; Dr Hua Ouyang; Ms Neera Shrestha Pradhan; Dr Arun Shrestha; Dr Mandira Shrestha; Dr Rajendra Shrestha; and Dr Shahriar Wahid. We appreciate their continuous support and interest throughout the project period.

The SGP research output papers published in this volume were thoroughly reviewed by: Dr Richard Armstrong, University of Colorado, USA; Professor Mukand Babel, Asian Institute of Technology, Thailand; Professor Jack Ives, Carleton University, Canada; Dr Lisa Schipper, Stockholm Environment institute, USA; and Professor Jon Lovett, Leeds University, UK. We appreciate their valuable contributions in finalizing these papers.

We express deep gratitude to our research partners in the SAWI countries, whose valuable contributions are published in this volume: Bangladesh (Centre for Environmental and Geographic Information Services); China (Asian International Rivers Centre at Yunnan University, Chinese National Committee on Irrigation and Drainage, and Peking University); India (GB Pant Institute of Himalayan Environment and Development, Sharda University, and South Asia Consortium for Interdisciplinary Water Resources Studies); Nepal (Central Department of Geography at Tribhuvan University, Institute for Development and Innovation, International Network on Participatory Irrigation Management - Nepal, Jalsrot Vikas Sanstha, Kathmandu University, and The Small Earth - Nepal); and Pakistan (Centre for Excellence in Water Resources Engineering at the University of Engineering and Technology, and National University of Science and Technology). 
We would also like to thank our consultant editor $\operatorname{Dr} A$ Beatrice Murray and the rest of the editorial and production team - Dharma R Maharajan, Asha Kaji Thaku, and Amy Sellmyer - and our administrative support team Sarita Joshi and Krisha Shrestha. 


\title{
Acronyms and Abbreviations
}

\author{
ADD Abu Dhabi Dialogue \\ ADDKF Abu Dhabi Dialogue Knowledge Forum (ADDKF) \\ AET actual evapotranspiration \\ AMT average monthly temperature \\ BC bias correction \\ BHIWA basin-wide holistic integrated water assessment \\ BP back propagation \\ $\mathrm{CBO}$ community-based organizations \\ CFUG community forest user group \\ DDC District Development Committee \\ DDF positive degree day factor \\ DSSAT Decision Support System for Agro-technology Transfer tool \\ EMC Environmental Monitoring Committee \\ ETO reference evapotranspiration \\ FAO Food and Agriculture Organization of the United Nations \\ FGD focus group discussion \\ FO farmer organizations \\ GBM Ganges-Brahmaputra-Meghna basin \\ GCM general circulation models \\ GDEM Global Digital Elevation Model \\ GIS geographical information system \\ GLOF glacial lake outburst flood \\ $\mathrm{HKH} \quad$ Hindu Kush Himalayas \\ ICID International Commission on Irrigation and Drainage \\ ICIMOD International Centre for Integrated Mountain Development (ICIMOD) \\ IPCC Intergovernmental Panel on Climate Change \\ IWRM integrated water resources management \\ KHEP Kulekhani Hydro Electricity Project \\ KII key informant interviews \\ LANCO Lagadapati Amarappa Naidu Company \\ LDOF landslide dam outburst flood \\ LSGR Local Self Governance Rules \\ NAPA National Adaptation Programme of Action \\ NEA Nepal Electricity Authority \\ NGO non-governmental organizations \\ NHPC National Hydroelectric Power Corporation, Government of India \\ PCA principal component analysis
}


PDD positive degree day

PES payments for ecosystem services

PET potential evapotranspiration

PIPIPP Punjab Irrigated Agriculture Productivity Improvement Programme Project

PRECIS Providing Regional Climates for Impact Studies model

R\&R resettlement and rehabilitation

RCM regional climate model

RCP representative concentration pathway

REA reliability ensemble averaging

SAWI South Asia Water Initiative

SDSM statistical downscaling model

SGP Small Grants Programme

SWAT soil and water assessment tool

TAR Tibet Autonomous Region

VDC village development committee

WRF Weather Research and Forecasting model 